show that bleeding can be closely defined and described as follows: (1) non-haemorrhagic: no bleeding either spontaneously or to light touch; (2) moderately haemorrhagic: bleeding to light touch, but no spontaneous bleeding seen ahead of instrument at initial inspection ; (3) severely haemorrhagic: spontaneous bleeding seen ahead of instrument at initial inspection with bleeding to light touch (blood on the surface of normal mucosa is thus excluded). Using a similar classification, we, taken in pairs and scoring independently, agreed in more than two out of three patients. There is no final evidence that the degree of haemorrhage from the mucosa is closely related to the severity of the disease, but there is good presumptive evidence that this is so.

Clinical conditions can be graded by summation of the scores of individual criteria as has been done for thyroid disease by Crooks et al. (1959). If a scoring system is not used the definitions for each grade must be mutually exclusive. If this is not so and two unrelated criteria are included in each grade, overlap will often occur so that it becomes impossible to fit some appearances into a single grade. This was one of the causes of failure of the definitions of "activity" used in Patients 1-30, because such a description as "dry, granular, friable" does not correspond to any grade.

\section{Summary}

Three observers recorded independently the sigmoidoscopic appearances of 60 patients with proctocolitis in a study of the observer variation of certain descriptive characteristics.

The observer variation for those characteristics requiring discrimination between poorly defined parts of a continuum, such as shades of colour, largely invalidate their use as comparative terms.

For other characteristics requiring the observer to record the presence or absence of a clearly defined feature, such as spontaneous bleeding and bleeding to light touch, there was less variation, and these assessments are meaningful.

A simple classification of the mucosal appearances in proctocolitis based on these particular characteristics is described.

\section{REFERENCES}

Baron, J. H. Connell, A. M., Lennard-Jones, J. E., and Jones, F. A. 1962). Lancet, 1, 1094

Crooks, J., Murray, I. P. C., and Wayne, E. J. (1959). Quart. F. Med., 28, 211.

Lockhart-Mummery, H. E. (1959). Proc. roy. Soc. Med., 52, Suppl (Anglo-American Conference on Proctology), p. 3.

\title{
Pneumococcal Meningitis in Pregnancy and the Puerperium
}

\author{
ADETOKUNBO O. LUCAS, ${ }^{*}$ M.B., B.SC., M.R.C.P., D.P.H., D.T.M.\&H.
}

Brit. med. F., 1964, 1, 92-95

Pneumococcal meningitis is a disease of world-wide distribution affecting both sexes and all age-groups from neonates to nonagenarians (Ruegsegger, 1942). Although there are isolated reports of this disease occurring in pregnancy and in the puerperium, the literature suggests that such an association is rare and fortuitous (MacQueen, 1927 ; Heinz, 1928 ; Laffont et al., 1933 ; Petersen, 1937 ; Nuckols and Hertig, 1938 ; Hutton 1956; Mahon et al., 1959). In Ibadan, cases of pneurnococcal meningitis in pregnant and recently delivered women are not uncommon. This paper is a report of 26 cases of pneumococcal meningitis in pregnant and puerperal women. Evidence is presented that pregnant and puerperal women in this area are more liable to pneumococcal meningitis than nonpregnant women, and the significance of the finding is discussed.

\section{Material and Methods}

This work is based on the study of all the adult cases with pneumococcal meningitis which were treated at the University College Hospital, Ibadan, between 1 January 1958 and 31 March 1962. I did not see the patients who were admitted before March 1960 at the acute stage of the illness. Data about these were obtained from case notes, although some of the survivors were traced and examined.

The diagnosis in each case was based on examination of the cerebrospinal fluid, which was obtained at necropsy in one patient who died before lumbar puncture could be performed. Stained smears of the fluid were examined and routine bacteriological methods were used for culture. Streptococcus pneu-

\footnotetext{
- Senior Registrar, Department of Medicine, University College Hospital, Ibadan, Nigeria.
}

moniae was identified by the optochin technique (Bowers and Jeffries, 1955). Other investigations on these patients included $x$-ray examination of the chest and paranasal sinuses, blood count and blood culture, and bacteriological examination of sputum or throat swab. Swabs were taken from the vaginal vault in 10 patients.

At an early stage of this investigation it was noted that most of the adult women patients with pneumococcal meningitis were either pregnant or had recently been delivered. In order to determine how far selection of patients was responsible for the high proportion of pregnant and puerperal patients, two other groups of hospital patients were studied: (1) all adult patients who were admitted to this hospital with other types of meningitis (pyogenic, tuberculous, and viral); and (2) all adult patients who were admitted with bacteriologically proved typhoid. Typhoid was chosen for comparison because it is an acute specific fever, commonly encountered in this area, the presenting symptoms being fever, mental confusion, and coma. The period covered was the same as for the pneumococcal meningitis patients. These cases were analysed by age and sex, and whether they were pregnant or recently delivered. A woman was regarded as being recently delivered up to two months after parturition or abortion.

The frequency of pregnant and puerperal cases was also determined in two other groups of patients.

1. Epidemic Meningococcal Meningitis.-In March 1962 a field survey was carried out in Northern Nigeria, where epidemics of meningococcal meningitis recur annually (Horn, 1951). Twenty-three treatment centres were visited and 277 patients were seen.

2. Lobar pneumonia, representing pneumococcal infection without meningitis.-The study was carried out in the general 
out-patient department of this hospital during October 1961 to February 1962 inclusive, and 109 adult patients were seen. Most patients who present with lobar pneumonia are treated at this clinic, admission being reserved for the seriously ill patients. The diagnosis was based on clinical and radiological findings.

\section{Results}

In the period under review, 77 adult Nigerian patients with pneumococcal meningitis were admitted. The age and sex distribution of the cases is shown in Table I, which also shows the number of patients who were pregnant or recently delivered.

TABLs I.-Age and Sex Distribution of 77 Adult Patients with Pneumococcal Meningitis

\begin{tabular}{l|c|c|c|c}
\hline $\begin{array}{c}\text { Age } \\
\text { Group } \\
\text { (Years) }\end{array}$ & Male & $\begin{array}{c}|c| \\
\text { Pregnant and } \\
\text { Recently } \\
\text { Delivered }\end{array}$ & Non-pregnant & Total \\
\hline $10-15$ & 10 & 0 & 7 & \\
$16-25$ & 7 & 12 & 2 & 17 \\
$26-35$ & 12 & 12 & 3 & 21 \\
$36-45$ & 4 & 2 & 0 & 6 \\
$45+$ & 5 & 0 & 1 & 6 \\
\hline Total & 38 & 26 & 13 & 77 \\
\hline
\end{tabular}

Of 31 female patients in the age group $16-45$ years 26 were either pregnant or recently delivered when they developed preumococcal meningitis. This paper is based on a study of these 26 patients. The organism was cultured from the crebrospinal fluid of 22 of these 26 . In four patients, Grampositive diplococci resembling Str. pneumoniae were seen in stained smears of the fluid, but bacteriological culture was sterile.

Origin of Pregnant and Puerperal Cases.-Only 6 of the 26 pregnant or recently delivered patients had been under medical supervision during their pregnancy. Two of these pregnant patients attended the antenatal clinic of this hospital; two were referred from other antenatal clinics when they developed meningitis; and two puerperal women were delivered under medical supervision outside this hospital. Eleven pregnant patients had had no antenatal care and nine puerperal patients had been delivered at home by unqualified persons.

Stage of Pregnancy.-The distribution of cases by stage of pregnancy is shown in Table II. Most cases occurred in late pregnancy and in the first week of the puerperium (Table III).

TABLE II.-Stage of Pregnancy in 26 Patients with Pneumococcal Meningitis

\begin{tabular}{|c|c|c|c|c|}
\hline \multicolumn{2}{|c|}{ Stage of Pregnancy } & Survived & Died & Total \\
\hline $\begin{array}{l}\text { 1st trimester } \quad . \\
\text { 2nd " } \\
\text { 3rd } \\
\text { Recently delivered }\end{array}$ & $\begin{array}{l}\ldots \\
\cdots \\
\cdots\end{array}$ & $\begin{array}{l}3 \\
2 \\
7 \\
7\end{array}$ & $\begin{array}{l}0 \\
3 \\
0 \\
4\end{array}$ & $\begin{array}{r}3 \\
5 \\
7 \\
11\end{array}$ \\
\hline Total .. & $\ldots$ & 19 & 7 & 26 \\
\hline
\end{tabular}

TABLE III.-Time of Onset of Pneumococcal Meningitis in the Puerperium

\begin{tabular}{c|c|c|c|c|c|c|c}
\hline No. of days after delivery & $0-3$ & -7 & -14 & -28 & $28+$ & Total \\
"n patients.. &.. & 4 & 4 & 1 & 1 & 1 &
\end{tabular}

The distribution is similar to that reported in the literature (Commandeur, 1908 ; MacQueen, 1927 ; Heinz, 1928 ; Laffont et al., 1933 ; Nuckols and Hertig, 1938; Hutton, 1956; Mahon et al., 1959). One late case which developed seven weeks after delivery is included. This patient was first seen on 26 March 1960, three weeks after the delivery of her baby at home. Lobar pneumonia was diagnosed and chest $x$-ray film showed consolidation of the left lower lobe. She did not complete the course of penicillin which was prescribed in the general out-patient clinic. One month later, on 27 April, she was admitted with pneumococcal meningitis. It seems likely that the pneumococcal infection was acquired during the puerperium.

Origin of Infaction.-The apparent primary infection was pneumonia in seven patients, four of whom died. Four patients had otitis media and one had sinusitis. More than half of the group (14 patients) had no obvious focus of infection (Table IV). The high incidence of primary pneumococcal meningitis has been noted by other workers in Africa (Hutton, 1956; Gelfand, 1957), and it is not peculiar to pregnant women. Str. pneumoniae was isolated from the vaginal vault in 3 out

TABLE IV.-Apparent Primary Infection in 26 Cases of Pneumococeal Meningitis in Pregnant and Puerperal Women

\begin{tabular}{|c|c|c|c|c|c|}
\hline \multicolumn{3}{|c|}{ Apparent Primary Infection } & Survived & Died & Total \\
\hline $\begin{array}{l}\text { Pneumonia } \\
\text { Suppurative } \\
\text { Sinusitis } \\
\text { None found }\end{array}$ & 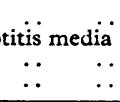 & $\begin{array}{l}\ldots \\
\therefore\end{array}$ & $\begin{array}{r}3 \\
4 \\
1 \\
11\end{array}$ & $\begin{array}{l}4 \\
0 \\
0 \\
3\end{array}$ & $\begin{array}{r}7 \\
4 \\
1 \\
14\end{array}$ \\
\hline & Total & $\ldots$ & 19 & 7 & 26 \\
\hline
\end{tabular}

of 10 patients from whom specimens were taken. Two were puerperal and one was post-abortal. The role of primary genital infection in the origin of pneumococcal meningitis in pregnant and recently delivered patients' is discussed later.

Associated Lesions and Complications.-Important coincidental diseases included anaemia and pyelonephritis. Two patients had a severe anaemia with haemoglobin level below 7 g. $/ 100 \mathrm{ml}$. One patient had a urinary infection with Escherichia coli which was resistant to all routine antibiotics tested. Another patient had episodes of paroxysmal supraventricular tachycardia. One patient had primary peritonitis which was presumed also to be pneumococcal. Two patients who also had pneumonia were jaundiced with serum bilirubin 3.7 and $5.1 \mathrm{mg} . / 100 \mathrm{ml}$. respectively.

Hyperpyrexia.-In four patients temperatures above $106^{\circ} \mathrm{R}$. $\left(41.1^{\circ} \mathrm{C}\right.$.) were recorded, the highest being $107.2^{\circ} \mathrm{F} .\left(41.8^{\circ} \mathrm{C} \text {. }\right)^{\text {. }}$. Two of these patients died. In this hospital hyperpyrexia is a frequent complication of other acute infections, such as typhoid and tetanus. Hyperpyrexia is a dangerous complication which calls for prompt treatment. Its onset can be sudden and unexpected. Early diagnosis, which is so vital for successfut treatment, is best ensured by recording the body temperature of these patients frequently.

Problems in Diagnosis.-The diagnosis of pneumococcal meningitis in pregnant women is easy in the average case presenting with fever, headache, and neck stiffness. Occasionally difficulty is encountered. Eclampsia may be suspected in the pregnant woman whose main presenting symptoms are epileptiform fits, especially if associated with hypertension and albuminuria. Epileptiform fits were observed in 10 of the 26 patients (Table V); in three patients the fits were Jacksonian

TABLE V.-Occurrence of Epileptiform Fits in 26 Cases of Pneumococal Meningitis in Pregnant and Puerperal Women

\begin{tabular}{|c|c|c|c|c|c|c|}
\hline \multicolumn{4}{|c|}{ Epileptiform Fits } & Survived & Died & Total \\
\hline $\begin{array}{l}\text { Generalized } \\
\text { Focal } \quad \cdots \\
\text { None } \quad . . \\
\end{array}$ & $\begin{array}{l}\cdots \\
\cdots \\
\end{array}$ & $\begin{array}{l}. \\
\cdots \\
.\end{array}$ & $\begin{array}{l}. . \\
\cdots \\
.\end{array}$ & $\begin{array}{r}5 \\
1 \\
13 \\
\end{array}$ & $\begin{array}{l}2 \\
2 \\
3\end{array}$ & $\begin{array}{r}7 \\
3 \\
16\end{array}$ \\
\hline & Total & . & . & 19 & 7 & 26 \\
\hline
\end{tabular}

in type. Some patients present a psychiatric picture with either hyperactivity, such as extreme restlessness, violent aggression, and excitement, or the opposite type in which the patient is adynamic and mute, with staring eyes and expressionless face, as in catatonic stupor. In the early stage neck stiffness may be absent, the only manifestations being fever and mild mental confusion. In patients seen at the late stage there may again be no stiffness of the neck and Kernig's sign may be negative. 
If the patient is in peripheral circulatory failure, resuscitation with intravenous fluids and vasopressor drugs may restore these reflex signs. Lumbar puncture in these cases will reveal the diagnosis. Numerous organisms may be seen on a stained smear and Str. pneumoniae will be positively identified on culture.

\section{Treatment and Prognosis}

In this paper no attempt is made to discuss the details of treatment. These patients were treated with large doses of crystalline penicillin, usually 12 million units or more a day by intramuscular or intravenous injection. In addition most of them had a sulphonamide, usually sulphadiazine by mouth, and some had corticosteroids.

\section{Fate of the Mother}

Seven of the patients died, giving a case fatality rate of $27 \%$. Fifteen were comatose when the diagnosis was made: six of these died. The prognosis was best in patients who had the least impairment of consciousness (Table VI).

TABLE VI.-Level of Consciousness on Diagnosis in 26 Cases of Pneumococcal Meningitis in Puerperal Women

\begin{tabular}{|c|c|c|c|c|c|}
\hline \multicolumn{3}{|c|}{ Level of Consciousness } & Survived & Died & Total \\
\hline $\begin{array}{l}\text { Conscious or drowsy } \\
\text { Semi-comatose } \\
\text { Comatose }\end{array}$ & $\begin{array}{l}\cdots \\
\cdots \\
\cdots\end{array}$ & $\begin{array}{l}\cdots \\
\cdots\end{array}$ & $\begin{array}{r}4 \\
5 \\
10\end{array}$ & $\begin{array}{l}0 \\
1 \\
6\end{array}$ & $\begin{array}{r}4 \\
6 \\
16\end{array}$ \\
\hline Total & .. & . . & 19 & 7 & 26 \\
\hline
\end{tabular}

Residual neurological damage was common in the survivors. Some of these lesions recovered, but of the 19 survivors 10 had neurological sequelae on discharge from hospital. Five patients had cranial-nerve lesions; two of them were deaf. The other cranial nerves affected were the third, sixth, seventh, and twelf th. Five patients had signs of extensive brain damage with severe emotional disturbance, aphasia, and neurological lesions such as hemiplegia and cranial-nerve palsy. The longterm prognosis of the latter group of patients is only fair; three patients who were seen six months to three years after discharge showed definite improvement, particularly with regard to speech and focal neurological damage, but mental retardation persisted.

\section{Outcome of the Pregnancy}

The fate of the pregnancy is considered at different stages of gestation.

First Trimester ( 3 Cases).-One patient aborted at 12 weeks, two days before admission, and another aborted while in hospital, three weeks after admission. The third patient threatened to abort at the onset of the illness, but the bleeding stopped and the pregnancy continued successfully.

Second Trimester (5 Cases).- Two pregnancies continued to term, two aborted, and one patient died undelivered.

Third Trimester ( 7 Cases).-One patient delivered a stillbirth and two patients had living premature babies, of which one died on the day of birth. Three pregnancies continued to term and the babies survived. One patient, who was at full term when she became ill, had a normal baby.

The foetal loss from abortion, stillbirth, and neonatal death was 7 out of 15 pregnancies.

Puerperium (11 Cases).-Since most of the deliveries took place at home without skilled attention, reliable information on the labour of these patients is not available. According to the histories obtained one baby was stillborn; the other patients delivered live babies, including one set of twins. Of the babies seen, two developed pneumonia within 72 hours of birth, one of which died. The newborn baby of a patient with pneumococcal meningitis may develop pneumonia or other pneumococcal infection (Heinz, 1928 ; Laffont et al., 1933). Although transplacental infection of the foetus can occur, the infants are usually infected during the neonatal period. A case might be made for routine antibiotic prophylaxis in these infants.

\section{Association of Pregnancy with Pneumococcal Meningitis}

It might be thought that the high incidence of pregnant and puerperal cases of pneumococcal meningitis in this series is determined by various factors of selection. Many pregnant women are already under medical supervision at antenatal clinics, but only 6 of the 26 patients in this series had had antenatal care. If unwell the pregnant woman or the newly delivered mother will perhaps seek medical aid sooner than the non-pregnant woman. In the busy out-patient clinic, where large numbers of ill patients are seen, it is likely that pregnant women receive preferential treatment. That such selection does not explain the high incidence of pregnant and recently delivered cases in this group of patients with pneumococcal meningitis is shown by comparison with patients who had other types of meningitis and with those who had bacteriologically proved typhoid fever. Table VII shows the number of pregnant

TABLE VII.-Incidence of Pregnant and Recently Delivered Cases in Three Groups of Female Patients Aged 16 to 45

\begin{tabular}{|c|c|c|c|c|}
\hline Disease & & Pregnant & Non-pregnant & Total \\
\hline $\begin{array}{l}\text { Pneumococcal meningitis } \\
\text { Other types of " " . . } \\
\text { Typhoid }\end{array}$ & $\begin{array}{l}\ldots \\
\cdots \\
\cdots\end{array}$ & $\begin{array}{r}26 \\
7 \\
9\end{array}$ & $\begin{array}{r}5 \\
25 \\
35\end{array}$ & $\begin{array}{l}31 \\
32 \\
44\end{array}$ \\
\hline Total & $\ldots$ & 42 & 65 & 107 \\
\hline
\end{tabular}

and puerperal women patients aged 16-45 years who were admitted with these three conditions over the same period.

Whereas $26(84 \%)$ of the 31 women with pneumococcal meningitis were pregnant or recently delivered, only $7(22 \%)$ of the 32 cases with other types of meningitis and $9(20 \%)$ of the 44 typhoid cases were pregnant or recently delivered. The difference is statistically significant $(P<0.001)$.

In the survey of epidemic cerebrospinal meningitis in Northern Nigeria, 277 patients of all ages were seen and examined. There were 48 female patients aged 16-45, of whom only $5(10 \%)$ were pregnant or recently delivered.

The occurrence of other pneumococcal infections in association with pregnancy is also of interest. Of 109 consecutive adult patients who were seen at this hospital with lobar pneumonia, 27 were women aged 16-45, and $12(44 \%)$ of these were pregnant or recently delivered.

\section{Discussion}

The findings in this study suggest that, at least in this area, the association of pneumococcal meningitis with pregnancy and the puerperium is not fortuitous, but that pregnancy predisposes to pneumococcal meningitis. Various workers have suggested that the African negro is peculiarly susceptible to pneumococcal infections. Pneumococcal pneumonia is common, and the lesions tend to be generalized rather than localized in the lungs. Primary pneumococcal meningitis is apparently more common than in Europeans (Heffron, 1939; Hutton, 1956). Association of pneumococcal meningitis with pregnancy and the puerperium may be yet another special feature of pneumococcal infection in the African negro. 
By what mechanism are pregnant and puerperal women in this area predisposed to pneumococcal meningitis ? It is known that pregnancy modifies the course of various infections (French, 1908 ; Sprunt et al., 1938). For example, adult indigenous Africans in this area have a high degree of immunity to malarial infection, but there is temporary loss of this immunity during pregnancy (Bruce-Chwatt, 1952 ; McGregor and Smith, 1956). Two infections affecting the nervous system are significantly influenced by pregnancy. Paralytic poliomyelitis is more common in pregnant women (Aycock, 1941 ; Priddle et al., 1952 ; Rindge, 1957). Some authors found that epidemic encephalitis occurred more frequently and was more severe in pregnant women, although this finding has been disputed (Roques, 1928). However, it is recognized that women who are infected while pregnant are more liable to develop Parkinsonism, and after recovery from acute encephalitis a subsequent pregnancy may precipitate Parkinsonism. Although these observations would suggest that the nervous system of the pregnant woman is particularly vulnerable, patients with other types of meningitis at this hospital and those with epidemic cerebrospinal meningitis in Northern Nigeria show no preponderance of pregnant and puerperal cases. Thus it seems that so far as pyogenic meningitis is concerned the increased susceptibility is specific for Str. pneumoniae.

Before the introduction of sulphonamides and antibiotics, pneumococcal pneumonia was a serious complication of pregnancy, with a much higher death rate than for non-pregnant women (French, 1908 ; Finland and Dublin, 1939 ; Heffron, 1939). The poorer prognosis is associated with a higher incidence of bacteriaemia in these pregnant women. Of the patients studied at this hospital, a high proportion of the women patients with lobar pneumonia were pregnant or recently delivered. This would suggest an increased risk of pneumonia during pregnancy, but a field survey is required to settle this point.

The culture of Str. pneumoniae from the vagina of a few patients raises the question of infection from the genital tract, although that organism is only occasionally isolated in cases of post-abortal or puerperal sepsis. Ascending infection of the female genital tract is regarded as the probable route of infection in some cases of primary pneumococcal peritonitis, particularly in young girls and in puerperal women. This can lead to bacteriaemia and thereby to meningitis. However, the peritoneum and the genital tract can be secondarily infected from a primary focus in the respiratory tract (Nuckols and Hertig, 1938). Although it may be relevant in puerperal and postabortal cases, ascending infection of the female genital tract is an unlikely route in pregnant women with pneumococcal meningitis. In patients who present with infection at various sites it may be difficult to determine the primary focus and the route of infection.

The greater liability of pregnant women to pneumococcal meningitis may be determined by the metabolic changes which occur in pregnancy. For instance, the production of hydrocortisone is higher in the pregnant than in the non-pregnant woman, the peak blood-level being in late pregnancy (Cope and Black, 1959). .Glaser et al. (1951) showed that animals which are treated with cortisone have a higher mortality if challenged with experimental pneumococcal infection. A similar deleterious effect has been demonstrated in infections with various organisms from viruses to protozoa and fungi (Lancet, 1960). Thus the hypercortisonism of pregnancy may reduce the resistance of the host, making her less efficient in localizing pneumococcal infection. Various authors have shown that protein depletion or vitamin deficiency can lower the resistance of experimental animals to pneumococcal infection (Robinson and Siegel, 1944 ; Wissler, 1947). Protein and vitamin deficiencies are common in this area, and the pregnant woman is particularly liable because of extra demands of the foetus.

This association of pneumococcal meningitis with pregnancy and the puerperium has not been recorded in other parts of the world, although it is apparently common in this area of Nigeria. The mechanism which determines this greater risk during pregnancy is not known. There is clearly a need for further study of the epidemiology of pneumococcal infections in this part of Africa.

\section{Summary}

Twenty-six cases of pneumococcal meningitis in pregnant and puerperal Nigerian women are reported. These represent one-third of all adult patients with pneumococcal meningitis who were treated at the University College Hospital, Ibadan, over a four-year period. Seven of the 26 patients died and there was a high incidence of residual neurological sequelae among the survivors. The foetal loss from abortion, stillbirth, and neonatal death was 7 out of 15 pregnancies. The findings in this study suggest that the pregnant or puerperal woman in this area is more susceptible to pneumococcal meningitis than the non-pregnant woman.

I wish to thank all the physicians and obstetricians on the staff of University College Hospital, Ibadan, who kindly allowed me access to their patients; Professor P. J. Collard for his help and advice; and Mr. S. I. Ogbuah, of the Medical Records Department. I am also grateful to Professor E. A. Cheeseman, Queen's University, Belfast, for statistical advice.

The epidemiological survey in Northern Nigeria was supported by a grant from the West African Institute for Medical Research.

\section{REPERENCES}

Aycock, W. L. (1941). New Engl. 7. Med., 225, 164.

Bowers, E. F., and Jeffries, L. R. (1955). f. clix. Path., 8, 58.

Bruce-Chwatt, L. J. (1952). Ann. trop. Med. Parasit., 46, 173.

Commandeur, F. (1908). Obstétrique, 1, 289.

Cope, C. L., and Black, E. (1959). Ұ. Obstet. Gynaec. Brit. Emp., 66, 404. Finland, M., and Dublin, T. D. (1939). 7. Aneer. med. Ass., 112, 1027. French, H. (1908). Brit. med. f., 1, 1029, 1100, 1165.

Gelfand, M. (1957). The Sick African, 3rd ed., p. 26. Juta, Capetown.

Glaser, R. J., Berry, J. W., Loeb, L. H., and Wood, W. B. (1951). 7. Lab. clin. Med., 38, 363.

Heffron, R. (1939). Pneumonia, p. 313. Commonwealth Fund, London.

Heinz, H. (1928). New Engl. 于. Med., 199, 218.

Horn, D. W. (1951). F. roy. sanit. Inst., 71, 573.

Hutton, P. W. (1956). E. Afr. med. F., 33, 209.

Laffont, Castanier, and Lavalle, E. (1933). Bull. Soc. Obstét. Gynéc. Paris, 22, 165.

Lancet, 1960, 2, 913.

McGregor, I. A., and Smith, D. A. (1952). Trans. roy. Soc. trop. Med. Hyg., 46, 403.

MacQueen, A. M. (1927). Brit. med. 7., 1, 325.

Mahon, R., Pery, G., Arne, L., and Lacaze, J. (1959). Bull. Féd. Soc. Gynéc. Obstéc. franç., 11, 495.

Nuckols, H. H., and Hertig, A. T. (1938). Amer. F. Obstet. Gynec., 35, 782.

Petersen, E. (1937). Acta obstet. gynec. scand., 17, 40.

Priddle, H. D., Lenz, W. R., Young, D. C., and Stevenson, C. S. (1952). Amer. F. Obstet. Gynec., 63, 408.

Rindge, M. E. (1957). New Engl. 7. Med., 256, 281.

Robinson, H. J., and Siegel, H. (1944). F. infect. Dis., 75, 127.

Roques, F. (1928). 7. Obstet. Gynaec. Brit. Emp., 35, 1.

Ruegsegger, J. M. (1942). Ann. intern. Med., 17, 693.

Sprunt, D. H., McDearman, S., and Raper, J. (1938). F. exp. Med., 67, 159.

Wissler, R. W. (1947). F. infect. Dis., 80, 250. 